Supporting Information

\title{
Motion-programmed Bar-coating Method with \\ Controlled Gap for High-speed Scalable Preparation of Highly Crystalline Organic Semiconductor Thin Films
}

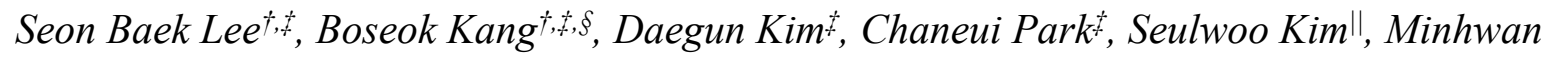
Lee ${ }^{\|}$, Won Bo Lee ${ }^{\|}$and Kilwon Cho ${ }^{*,+}$

tDepartment of Chemical Engineering and Center for Advanced Soft Electronics, Pohang University of Science and Technology, 77 Cheongam-Ro, Nam-Gu, Pohang 37673, Korea.

§SKKU Advanced Institute of Nanotechnology and Department of Nano Engineering, Sungkyunkwan University (SKKU), Suwon 16419, Korea.

"School of Chemical and Biological Engineering, Seoul National University, 1 Gwanak-Ro, Gwanak-Gu, Seoul 08826, Korea.

†These authors contributed equally to this work.

*e-mail: kwcho@postech.ac.kr 


\section{Table of Contents}

1. Supporting Figures (Figures $\mathrm{S} 1$ to S20)

Figure S1. The photograph and description of the wire-bar coater.

Figure S2. Differential scanning calorimeter data of $\mathrm{C}_{8}$-BTBT and PTAA.

Figure S3. The POM images of three different size of crystals. The size of large crystal is more than 1-2 mm continuous film, that of middle is about $2-300 \mu \mathrm{m}$, and that of small is about 5 $\mu \mathrm{m}$.

Figure S4. The POM images of blend film of diF-TESADT.

Figure S5. The height of stripes measured by Alpha-step.

Figure S6. The atomic force microscopy (AFM) images of $\mathrm{C}_{8}$-BTBT homo film and C8BTBT/PTAA blend film.

Figure S7. The POM images of P3HT/PTAA and $\mathrm{C}_{8}$-BTBT/PTAA.

Figure S8. The computational fluid dynamics (CFD) simulation.

Figure S9. The pole figures at the (002) peaks and full width at half maximum (FWHM).

Figure S10. The polarized UV-vis spectroscopy data.

Figure S11. The capacitance of dual-dielectric for Cytop ${ }^{\mathrm{TM}}$ and Parylene measured at $1 \mathrm{kHz} /$ $10 \mathrm{kHz}$ frequency.

Figure S12. The electrical characteristic of transfer curves of $\mathrm{C}_{8}$-BTBT/PTAA devices indicating the Cytop ${ }^{\mathrm{TM}}$ interlayer effect.

Figure S13. The electrical characteristics of top-contact bottom-gate (TCBG) OTFT device.

Figure S14. The electrical characteristics of output curve of $\mathrm{C}_{8}$-BTBT/PTAA.

Figure S15. The electrical characteristics of transfer curves of $\mathrm{C}_{10}$-BTBT, $\mathrm{C}_{12}$-BTBT and diFTESADT.

Figure S16. The $V_{G}$-dependent of the electrical transconductance curve of the $\mathrm{C}_{8}$-BTBT/PTAA blend film.

Figure S17. The energy level diagram of $\mathrm{C}_{8}$-BTBT, PTAA and Au electrode.

Figure S18. The contact resistance measured by Y-function method.

Figure S19. The environmental stability of device performance of field-effect-transistor mobility.

Figure S20. The activation plot of the measured mobility with various temperature.

Figure S21. Change of field-effect mobilities $\left(\mu_{\mathrm{FET}}\right)$ and threshold voltage $\left(V_{\mathrm{th}}\right)$ of flexible OTFT devices as a function of bending radius.

\section{Supporting Tables (Tables $\mathrm{S} 1$ to $\mathrm{S} 5$ )}

Table S1. Determining the solubility parameter.

Table S2. The contact angle and surface tension of deionized (DI) water and diiodomethane (DII) of each film.

Table S3. Summary for crystallographic information of bar-coating $\mathrm{C}_{8}$-BTBT/PTAA films along the parallel $(/ /)$ and perpendicular $(\perp)$ directions.

Table S4. The electrical performance of small molecules and polymer blend films.

Table S5. The comparison of OTFTs in terms of the coating method, coating speed, coating area, and mobility.

\section{Supporting Movies (Movies S1 to S2)}

Movie S1. The overall process of bar coating method.

Movie S2. The in-situ POM video of crystal growth at the different gap distances.

\section{References}




\section{Supporting Figures}
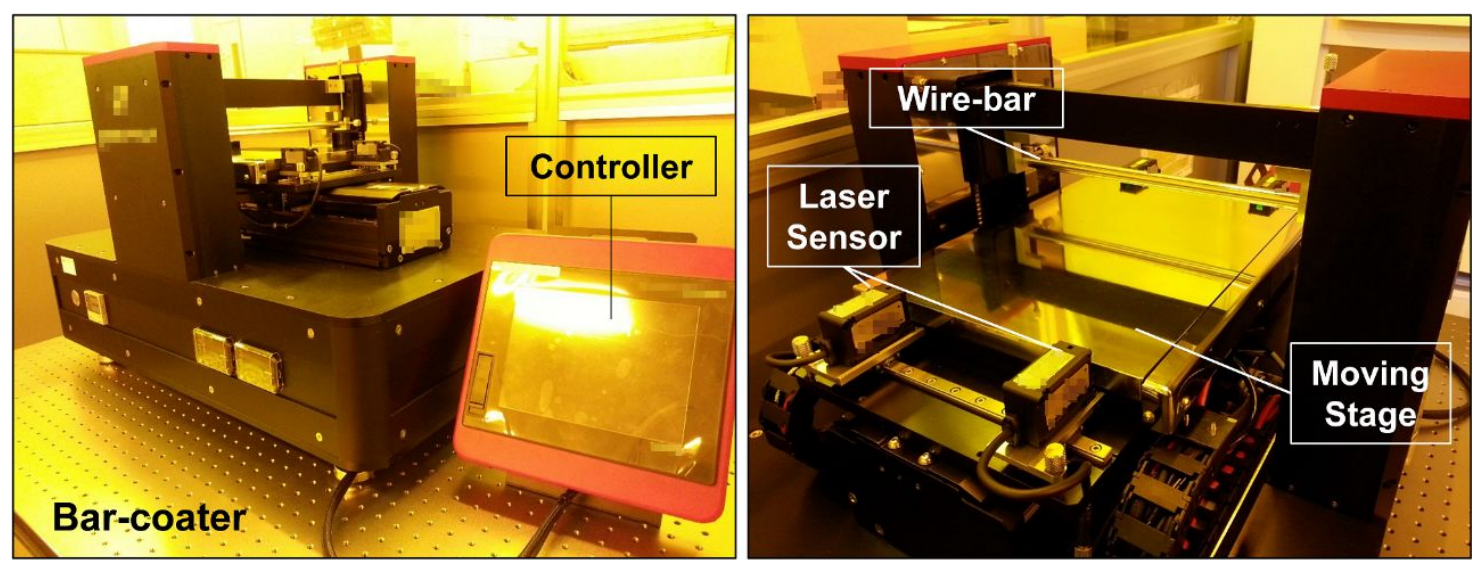

Figure S1. The photograph and description of the wire-bar coater. 

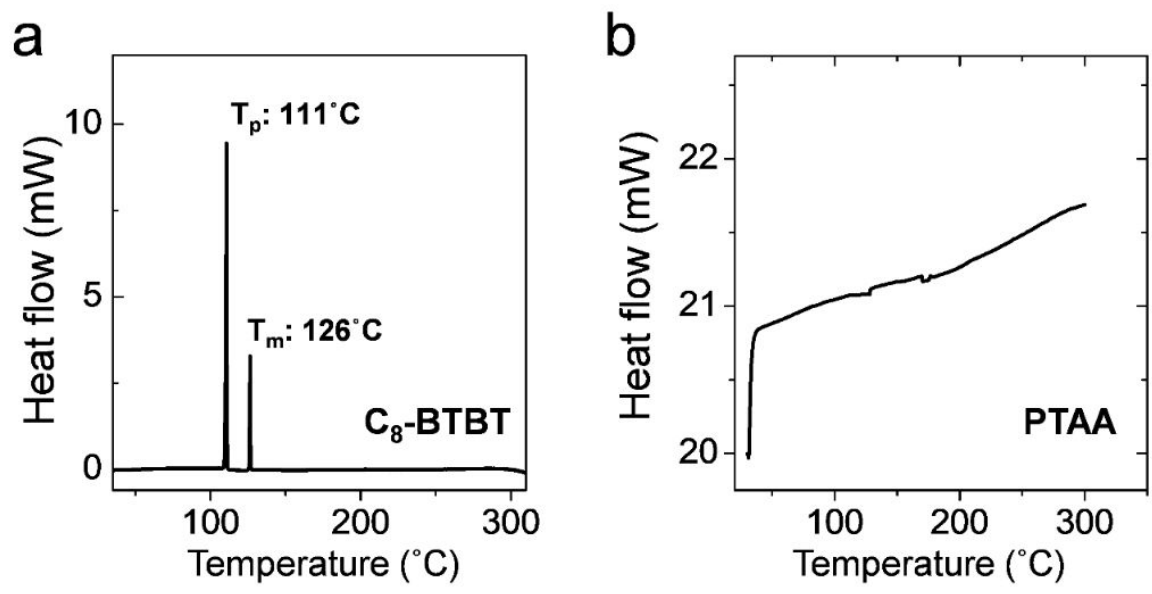

Figure S2. Differential Scanning Calorimeter (DSC) data of $\mathrm{C}_{8}$-BTBT and PTAA. (a) The DSC data for $\mathrm{C}_{8}$-BTBT with the phase transition temperature $\left(T_{\mathrm{p}}\right)$ near $111^{\circ} \mathrm{C}$, and the melting temperature $\left(T_{\mathrm{m}}\right)$ near $126^{\circ} \mathrm{C}$. (b) The DSC data for PTAA. 

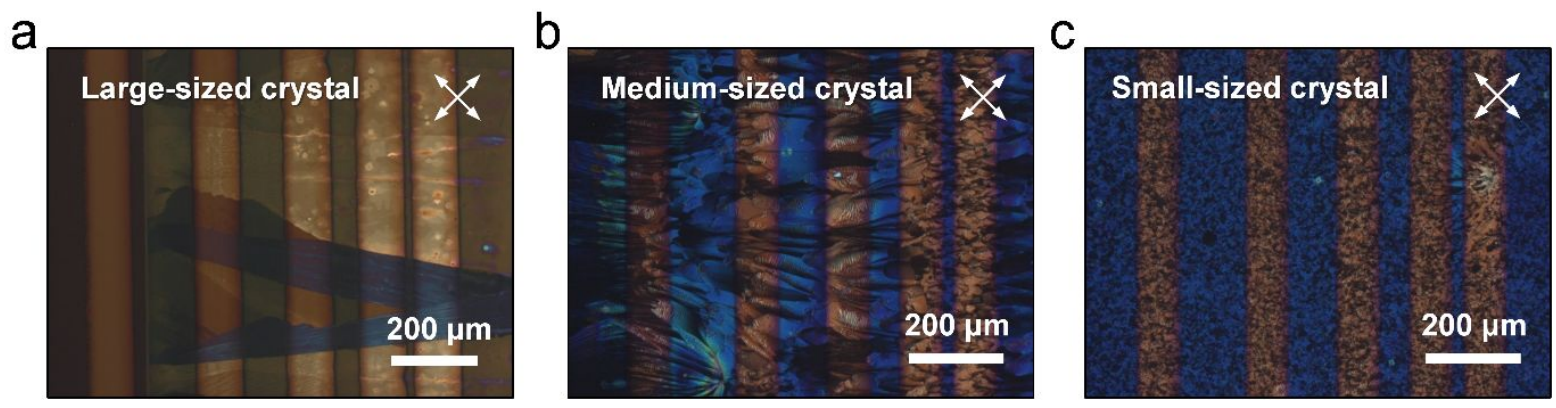

Figure S3. The POM images of bar-coated $\mathrm{C}_{8}$-BTBT/PTAA films with three different size of crystals. The sizes of crystals are (a) more than 1-2 mm, (b) about 200-300 $\mu \mathrm{m}$, and (c) about $5 \mu \mathrm{m}$, respectively. 
a
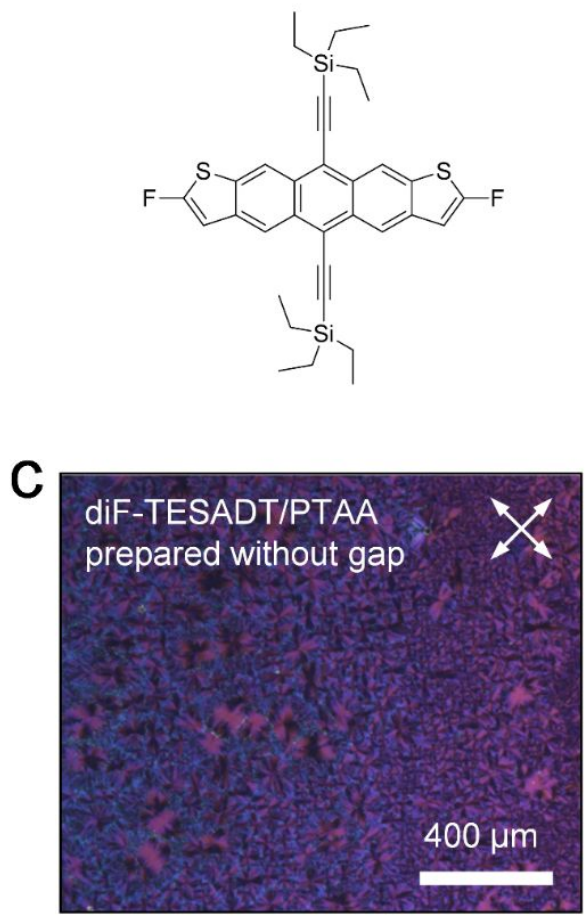

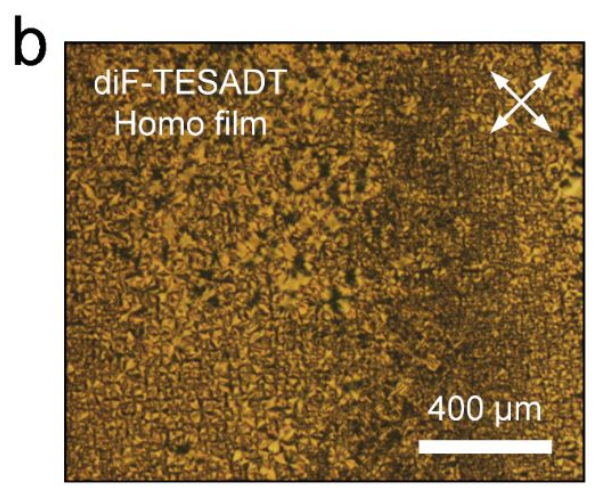

d

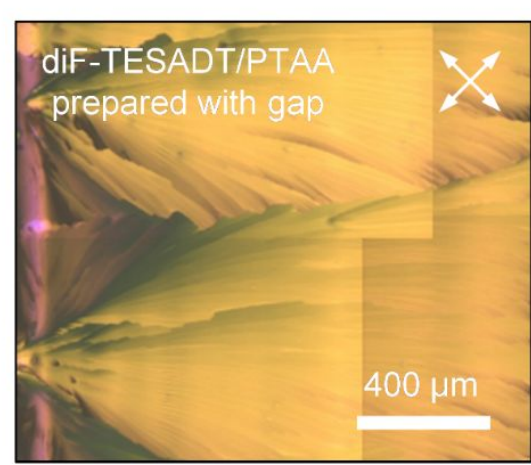

Figure S4. The POM images for bar-coated diF-TESADT homo or blend films. (a) The chemical structure of diF-TESADT. (b) The POM image of a homo diF-TESADT film ( $d^{\text {gap }}=$ $\left.2 \mu \mathrm{m}, v^{\mathrm{bar}}=1 \mathrm{~mm} \mathrm{~s}^{-1}\right)$. The POM images of diF-TESADT/PTAA blend films prepared using a motion-programmed bar : (c) $d^{\text {gap }}=0 \mu \mathrm{m}$ and (d) $d^{\text {gap }}=2 \mu \mathrm{m}$. 

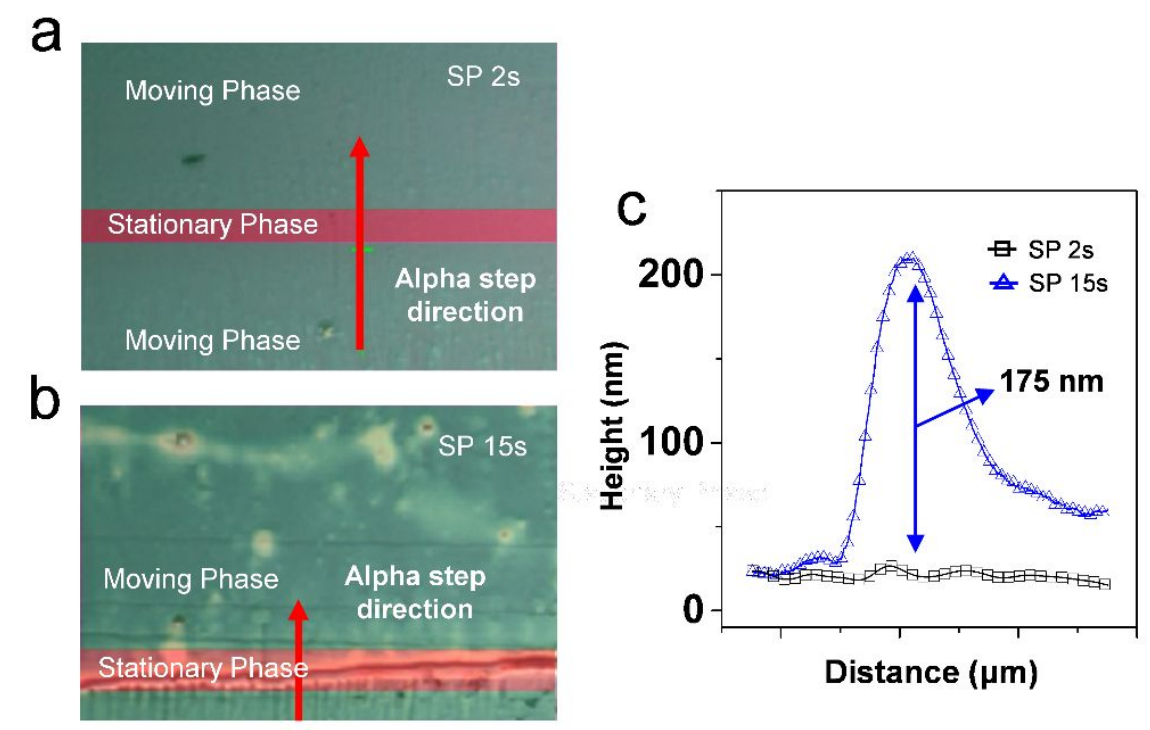

Figure S5. The height profiles of the stripes. The optical images of the stripes at the bar-coated $\mathrm{C}_{8}$-BTBT/PTAA films with (a) $t^{\text {stationary }}=2 \mathrm{~s}$ and (b) $t^{\text {stationary }}=15 \mathrm{~s}$. (c) The surface height profiles along the arrow direction. 


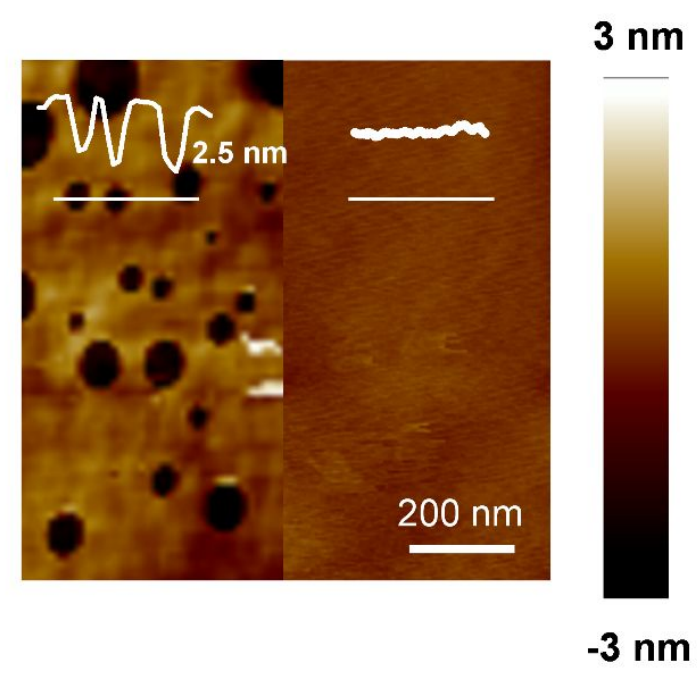

Figure S6. The atomic force microscopy (AFM) images of $\mathrm{C}_{8}$-BTBT homo film (left) and $\mathrm{C}_{8^{-}}$ BTBT/PTAA blend film. 

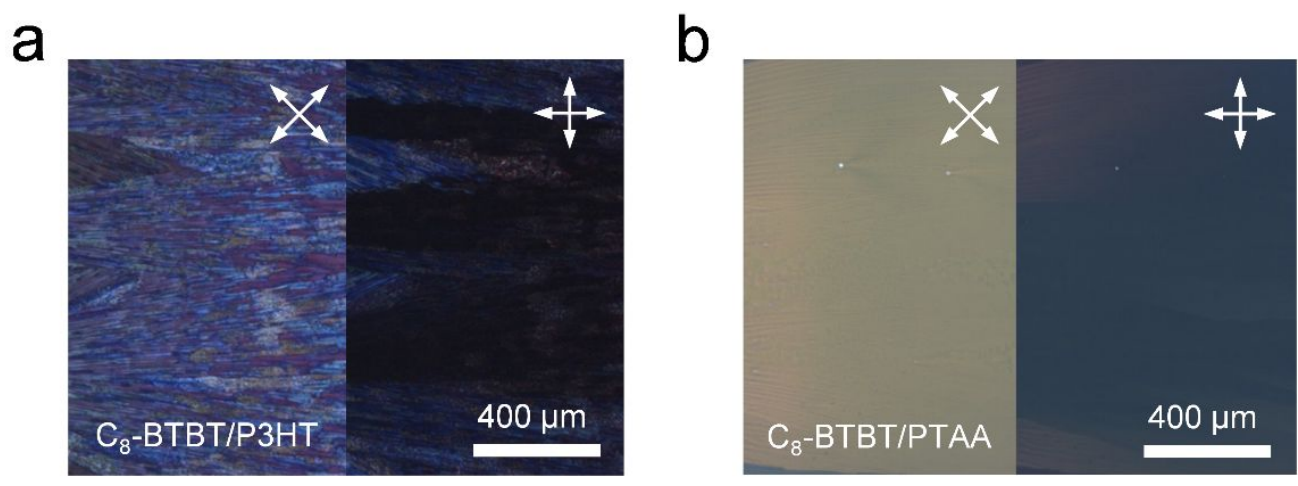

Figure S7. The POM images of P3HT/PTAA and $\mathrm{C}_{8}$-BTBT/PTAA. (a) $\mathrm{C}_{8}$-BTBT blend with semi-crystal polymer P3HT, and (b) amorphous polymer PTAA, and with the two different polarization angles $\left(45^{\circ}\right.$ and $\left.90^{\circ}\right)$ 


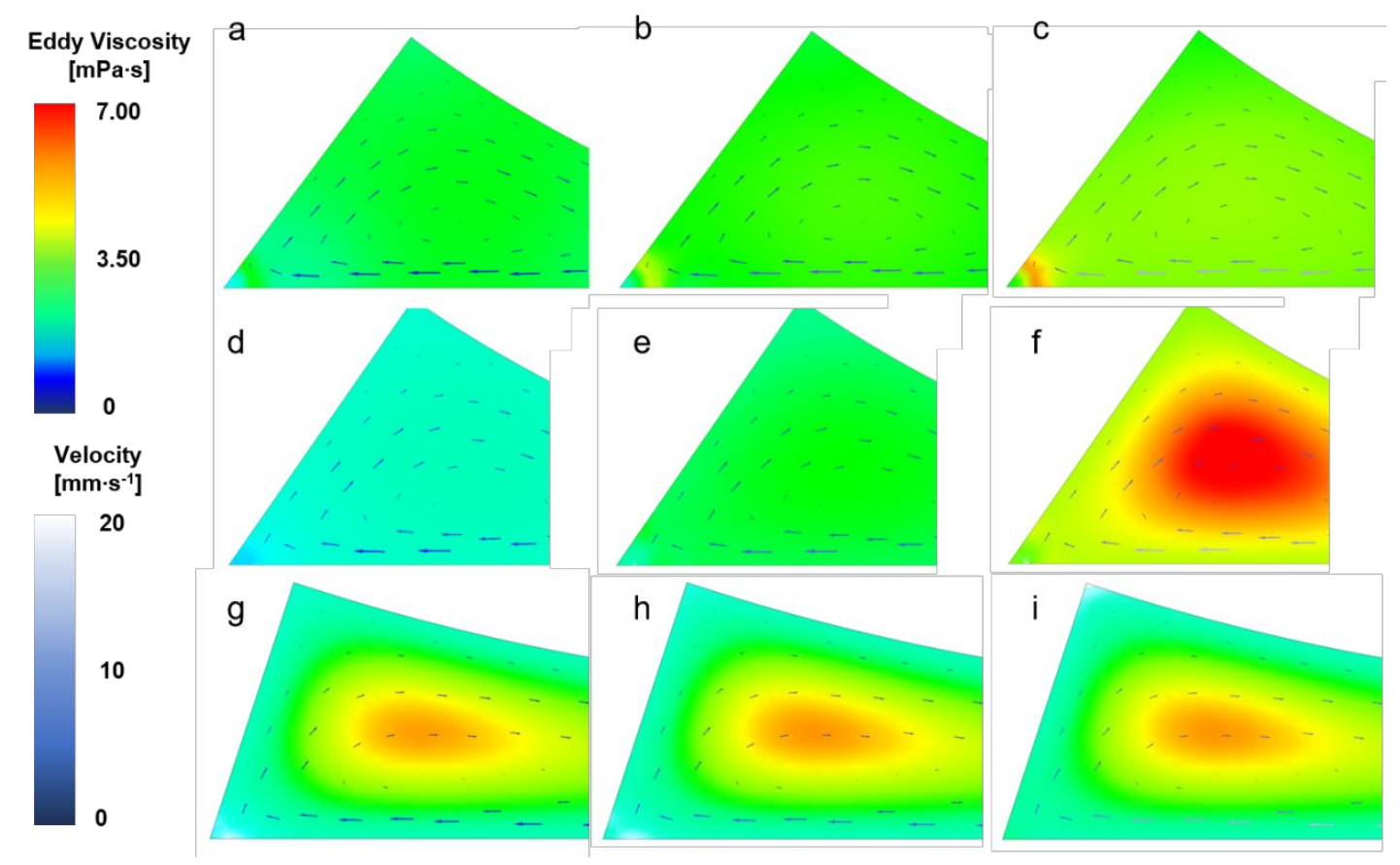

Figure S8. The computational fluid dynamics (CFD) Simulation results. The gap distances are $(\mathrm{a}, \mathrm{b}, \mathrm{c}) 10 \mu \mathrm{m},(\mathrm{d}, \mathrm{e}, \mathrm{f}) 200 \mu \mathrm{m}$, and $(\mathrm{g}, \mathrm{h}, \mathrm{i}) 400 \mu \mathrm{m}$, respectively. 


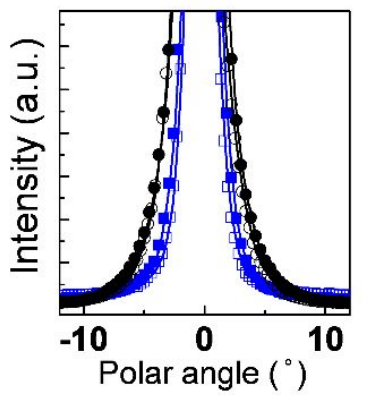

Figure S9. The pole figures at the (002) peaks: blue lines for large crystals and black lines for small crystals. Full width at half maximum (FWHM) values are found to $2.789^{\circ}$ and $2.327^{\circ}$ for the parallel and perpendicular directions with respect to the bar-coating direction in large crystals, and $3.829^{\circ}$ and $3.649^{\circ}$ for the parallel and perpendicular directions of small crystals. 

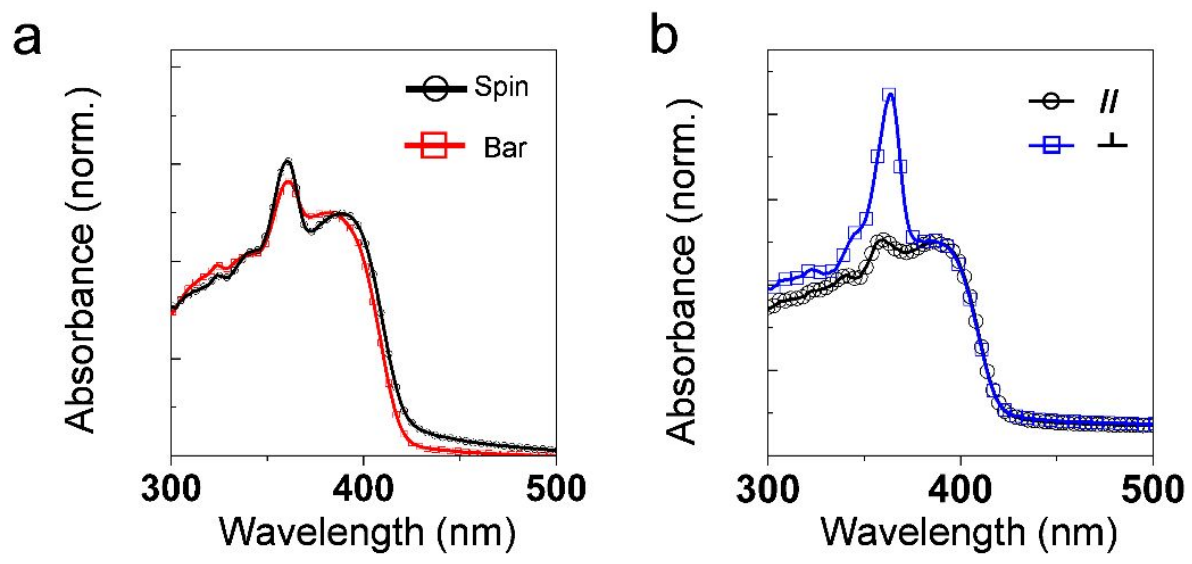

C

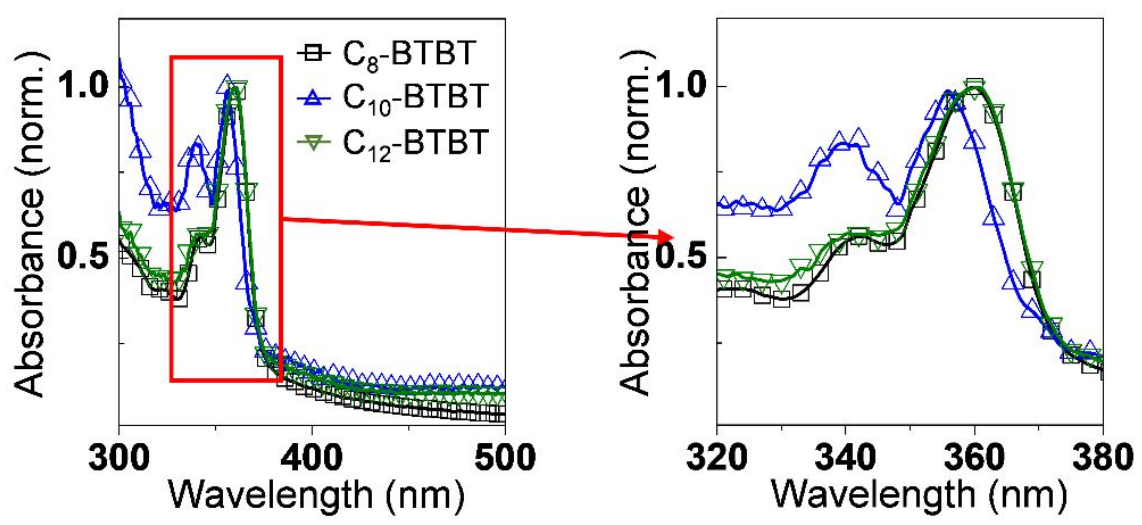

Figure S10. The polarized UV-vis spectroscopy data. (a) The data of $\mathrm{C}_{8}$-BTBT/PTAA of spincoating and bar-coating. (b) The data of $\mathrm{C}_{10}$-BTBT/PTAA large crystal of bar-coating with parallel and perpendicular. (c) The data of $\mathrm{C}_{8}$-BTBT, $\mathrm{C}_{10}$-BTBT, $\mathrm{C}_{12}$-BTBT homo film and the expanded data from $320 \mathrm{~nm}$ to $380 \mathrm{~nm}$ wavelength. 


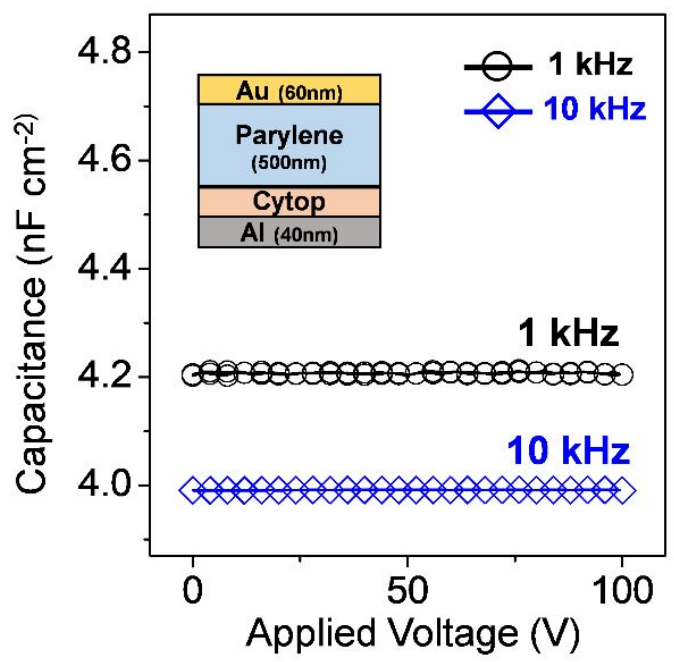

Figure S11. The capacitance-voltage plots of dual gate-dielectric consisting of Cytop ${ }^{\mathrm{TM}}$ and Parylene layers, where the data were measured at $1 \mathrm{kHz}$ and $10 \mathrm{kHz}$ frequency. The inset shows the metal-insulator-metal device structure. 


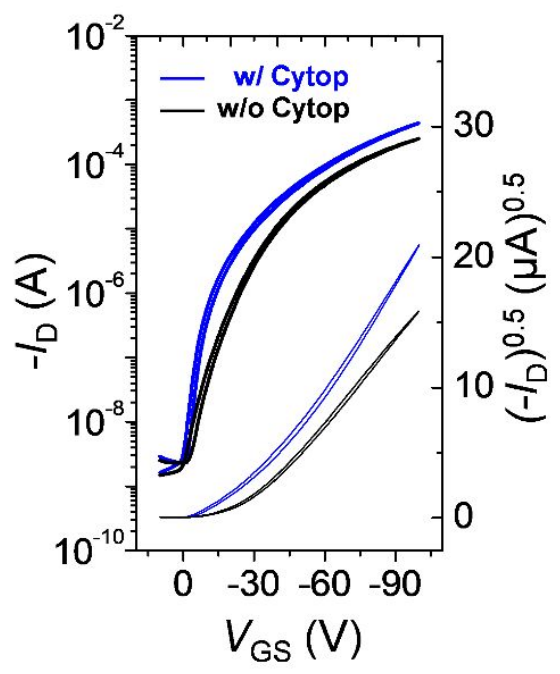

Figure S12. The transfer characteristics of bar-coated $\mathrm{C}_{8}$-BTBT:PTAA TFT devices with and without a Cytop ${ }^{\mathrm{TM}}$ interlayer. 


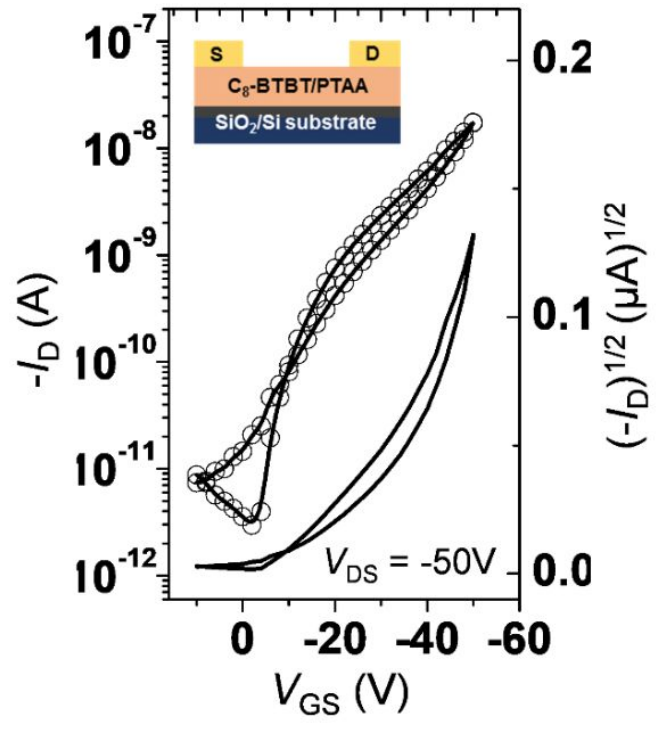

Figure S13. The electrical characteristics of top-contact bottom-gate (TCBG) OTFT device. The electrical transfer curve of TCBG OTFT has a charge carrier pathway at the buried interface so that showing low mobility of $\mu_{\max }=6.8 \times 10^{-4} \mathrm{~cm}^{2} \mathrm{~V}^{-1} \mathrm{~s}^{-1}$. 


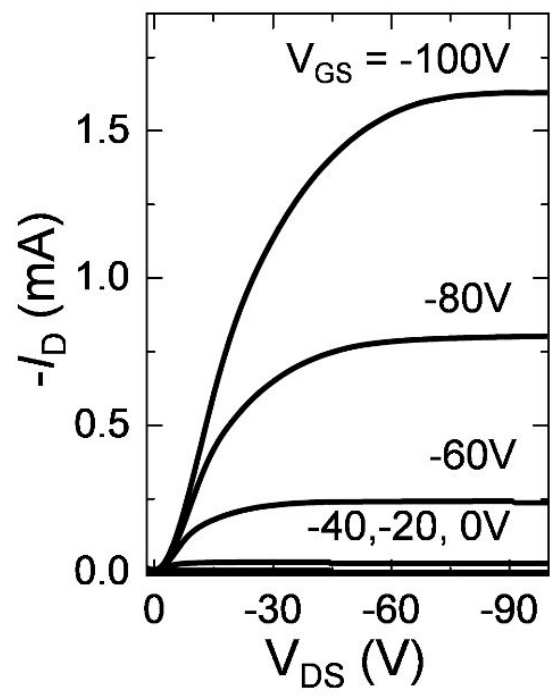

Figure S14. The electrical characteristics of output curve of $\mathrm{C}_{8}$-BTBT/PTAA. 

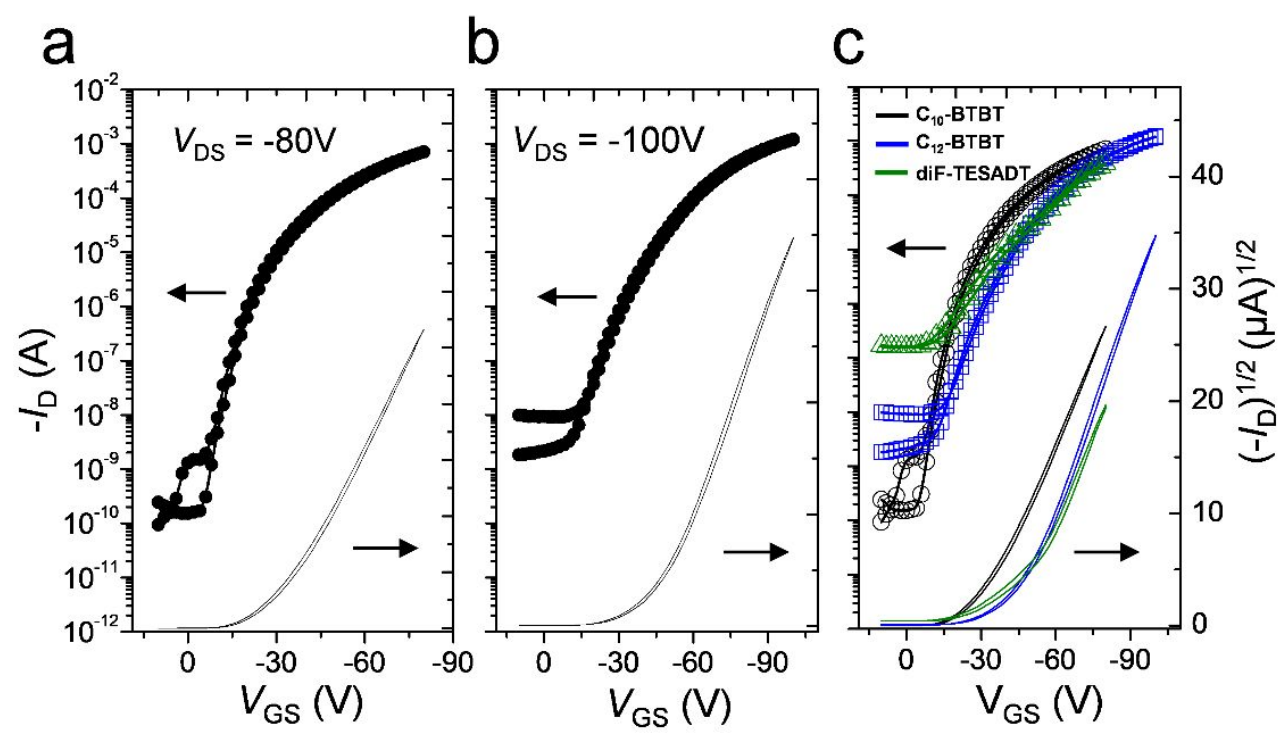

Figure S15. The transfer characteristics of bar-coated OTFT devices: (a) $\mathrm{C}_{10}$-BTBT/PTAA $\left(\mu_{\mathrm{FET}}=24.4 \mathrm{~cm}^{2} \mathrm{~V}^{-1} \mathrm{~s}^{-1}\right)$, (b) $\mathrm{C}_{12}$-BTBT/PTAA $\left(\mu_{\mathrm{FET}}=21.7 \mathrm{~cm}^{2} \mathrm{~V}^{-1} \mathrm{~s}^{-1}\right)$, and (c) homo $\mathrm{C}_{10^{-}}$ BTBT, homo $\mathrm{C}_{12}$-BTBT and diF-TESADT/PTAA blend. 


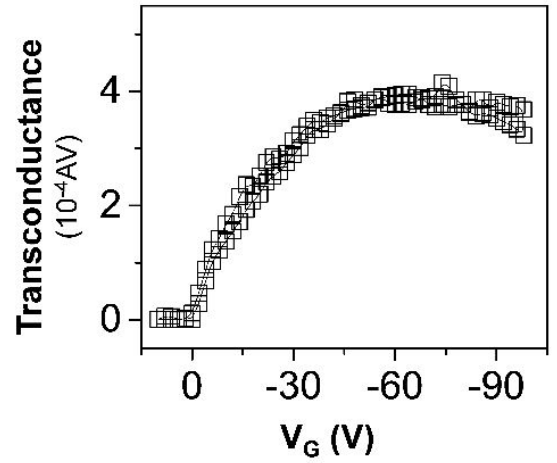

Figure S16. The $V_{G}$-dependent of the electrical transconductance curve of the $\mathrm{C}_{8}$-BTBT/PTAA blend film. 


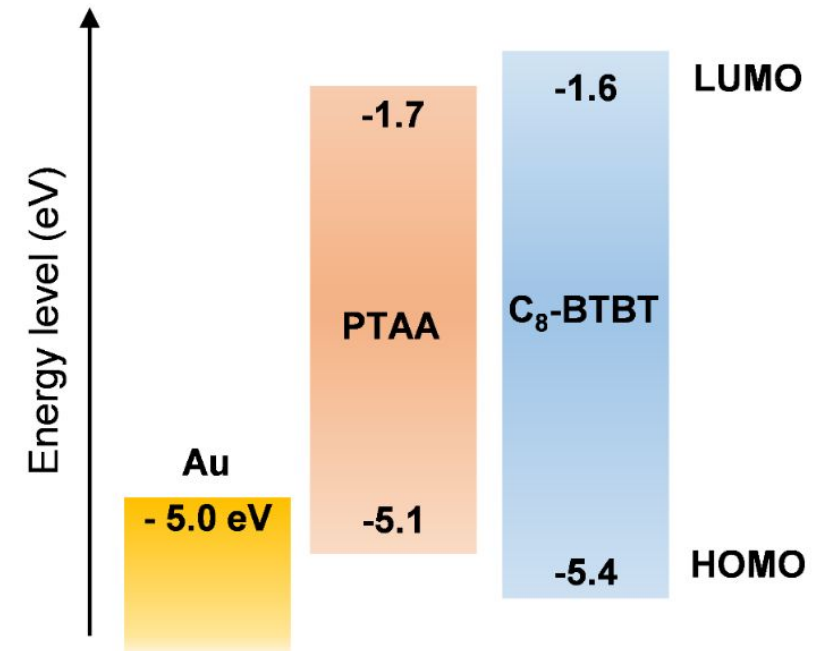

Figure S17. The energy level diagram of $\mathrm{C}_{8}$-BTBT, PTAA, and Au layers. 

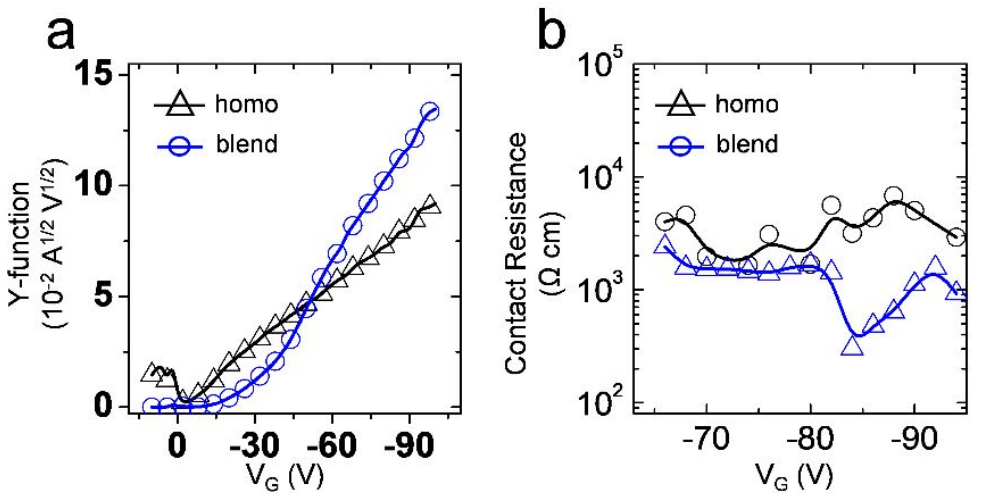

Figure S18. The contact resistance measured by the $\mathrm{Y}$-function method. (a) The $\mathrm{Y}$ functions plots of the $\mathrm{C}_{8}$-BTBT homo film and $\mathrm{C}_{8}$-BTBT/PTAA blend films. (b) The contact resistances evaluated by $\mathrm{Y}$-function as a function of gate voltage. 


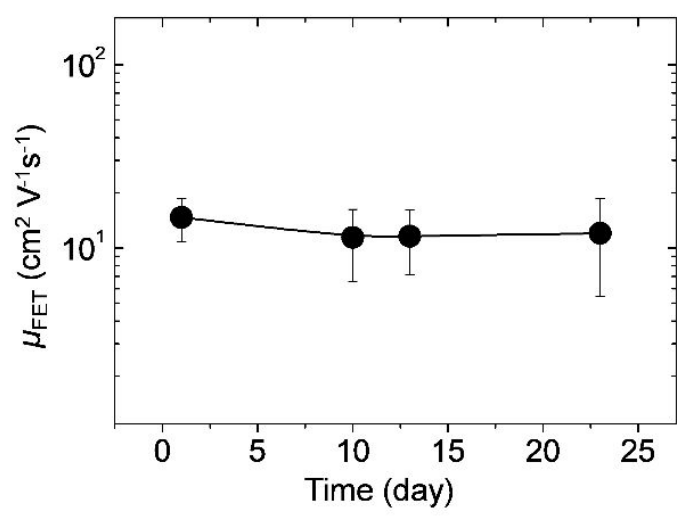

Figure S19. The long-term environmental stability of bar-coated $\mathrm{C}_{8}$-BTBT/PTAA TFTs 

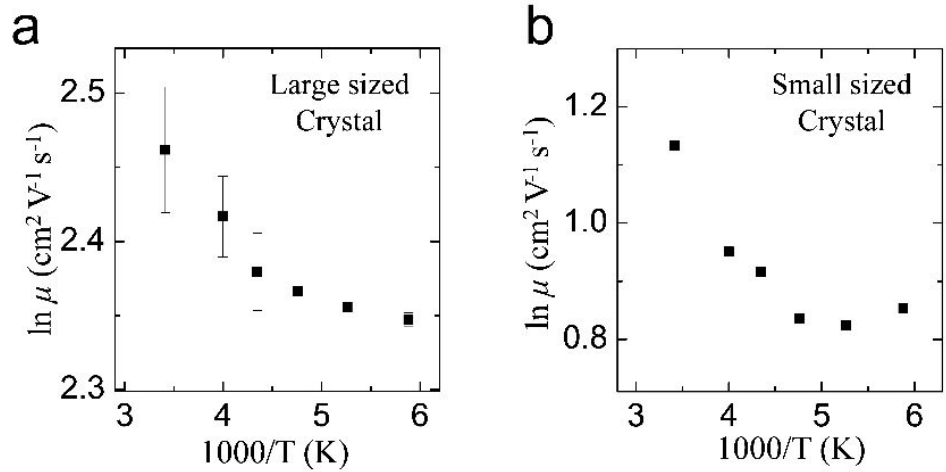

Figure S20. The plot of the measured mobility as a function of temperature for (a) large sized crystal films $\left(E_{\mathrm{a}}=5.54 \mathrm{eV}\right)$ and (b) small sized crystal films $\left(E_{\mathrm{a}}=9.5 \mathrm{eV}\right)$. 


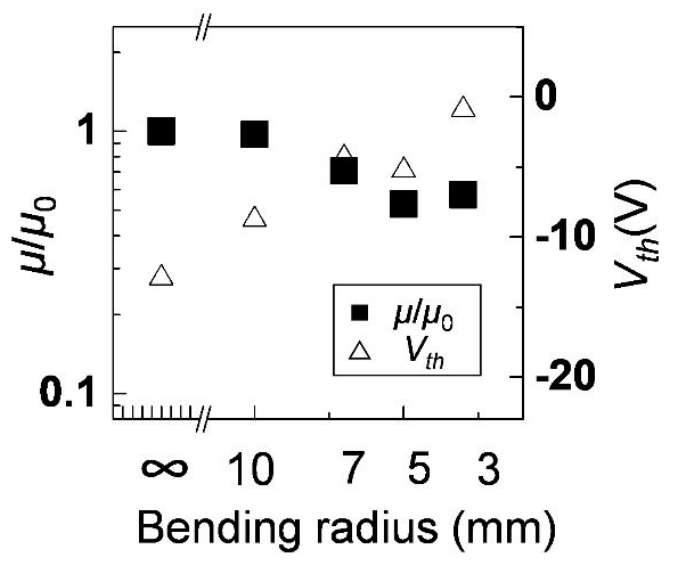

Figure S21. Change of field-effect mobilities $\left(\mu_{\mathrm{FET}}\right)$ and threshold voltage $\left(V_{\mathrm{th}}\right)$ of flexible OTFT devices as a function of bending radius. 


\section{Supporting Tables}

Table S1. Determining the solubility parameter with using following equation:

$\boldsymbol{\delta}=\rho \cdot \sum_{\bar{M}}^{G},{ }^{[\mathrm{S} 1]}$ where $\rho$ is the density, $G$ is the group molar attraction and $M$ is the molecular weight.

\begin{tabular}{cc}
\hline Materials & Solubility Parameter, $\boldsymbol{\delta}\left(\mathbf{M P a}^{\mathbf{1 / 2}}\right)$ \\
\hline diF-TES ADT & 15.5 \\
C $_{8}$-BTBT & 16.62 \\
TIPS-Pentacene & 18.5 \\
PTAA & 23.1 \\
\hline
\end{tabular}


Table S2. The surface energy on different organic films measured using two probe solvent of deionized water and diiodomethane.

\begin{tabular}{cccccc}
\hline & \multicolumn{2}{c}{$\begin{array}{c}\text { Contact angle } \\
\left(\mathbf{~ o}^{\mathbf{0}}\right.\end{array}$} & \multicolumn{3}{c}{$\begin{array}{c}\text { Surface energy } \\
\left(\mathbf{m J} \mathbf{~ m}^{-2}\right)\end{array}$} \\
\cline { 2 - 6 } Materials & DI water & Diiodomethane & $\gamma_{s}^{d}$ & $\gamma_{s}^{p}$ & $\gamma_{s}$ \\
\hline C $_{8}$-BTBT & 68 & 56 & 30.9 & 11.4 & 42.3 \\
PTAA & 91 & 22 & 47.2 & 0.3 & 47.5 \\
Cytop $^{\mathrm{TM}}$ & 111 & 87 & 14.1 & 0.7 & 14.8 \\
Parylene-C & 93 & 34 & 42.5 & 0.3 & 42.8 \\
\hline
\end{tabular}

A blend of the small molecule $\mathrm{C}_{8}$-BTBT and the binder polymer PTAA may induce vertical phase separation due to the difference of solubility parameter and surface energy (table $\mathrm{S} 1)$. The large difference in the solubility parameter of $\mathrm{C}_{8}$-BTBT $\left(16.62 \mathrm{MPa}^{1 / 2}\right)$, and PTAA (23.1 $\mathrm{MPa}^{1 / 2}$ ) provided a strong driving force for phase separation. In addition, the surface energy of PTAA $\left(47.5 \mathrm{~mJ} \mathrm{~m}^{-2}\right)$ is higher than $\mathrm{C}_{8}$-BTBT $\left(42.3 \mathrm{~mJ} \mathrm{~m}^{-2}\right)$, and PTAA with the high surface energy prefers to precipitate toward the UV-ozone treated hydrophilic substrate inducing vertical phase separation. 
Table S3. Summary of crystallographic information of bar-coating $\mathrm{C}_{8}$-BTBT/PTAA films, where the GIWAXS patterns were measured along the parallel $(/ /)$ and perpendicular $(\perp)$ directions to the bar-coating direction.

\begin{tabular}{|c|c|c|c|c|c|c|c|c|c|}
\hline & & \multicolumn{2}{|c|}{ Equilibrium } & \multicolumn{2}{|c|}{ Polymorph } & \multicolumn{2}{|c|}{ Equilibrium } & \multicolumn{2}{|c|}{ Polymorph } \\
\hline & & $\begin{array}{l}q^{(002)} \\
\left(\AA^{-1}\right)\end{array}$ & $\begin{array}{l}d^{(002)} \\
\left(\AA^{-1}\right)\end{array}$ & $\begin{array}{l}q^{(002)} \\
\left(\AA^{-1}\right)\end{array}$ & $\begin{array}{l}d^{(002)} \\
\left(\AA^{-1}\right)\end{array}$ & $\begin{array}{l}q^{(11 L)} \\
\left(\AA^{-1}\right)\end{array}$ & $\begin{array}{l}d^{(11 L)} \\
\left(\AA^{-1}\right)\end{array}$ & $\begin{array}{l}q^{(11 L)} \\
\left(\AA^{-1}\right)\end{array}$ & $\begin{array}{l}d^{(11 \mathrm{~L})} \\
\left(\AA^{-1}\right)\end{array}$ \\
\hline \multirow{2}{*}{$\begin{array}{c}\text { Large } \\
\text { Crystal }\end{array}$} & $/ /$ & 0.4333 & 14.50 & 0.4535 & 13.85 & 1.312 & 4.79 & 1.321 & 4.75 \\
\hline & $\perp$ & 0.4357 & 14.42 & 0.4548 & 13.82 & 1.306 & 4.81 & 1.339 & 4.69 \\
\hline \multirow{2}{*}{$\begin{array}{c}\text { Small } \\
\text { Crystal }\end{array}$} & $/ /$ & 0.4390 & 14.31 & 0.4559 & 13.78 & 1.335 & 4.71 & 1.351 & 4.65 \\
\hline & $\perp$ & 0.4365 & 14.39 & 0.4537 & 13.85 & 1.317 & 4.77 & 1.344 & 4.68 \\
\hline
\end{tabular}


Table S4. The electrical properties of various small molecules/polymer blend TFT devices prepared with different processing conditions.

\begin{tabular}{|c|c|c|c|c|c|c|}
\hline & Condition & & & & & \\
\hline OSCs & $\begin{array}{c}\text { Solution } \\
\text { concentration } \\
(w t \%)\end{array}$ & $\begin{array}{c}\text { Small- } \\
\text { molecule } \\
\text { contents } \\
(\%)\end{array}$ & $\begin{array}{c}\mu_{\max } \\
\left(\mathrm{cm}^{2} \mathrm{~V}^{-1} \mathrm{~s}^{-1}\right)\end{array}$ & $\begin{array}{c}\mu_{\text {avg }} \\
\left(\mathrm{cm}^{2} \mathrm{~V}^{-1} \mathrm{~s}^{-1}\right)\end{array}$ & $\begin{array}{l}V_{\mathrm{T}} \\
(\mathrm{V})\end{array}$ & $I_{\text {on }} / I_{\text {off }}$ \\
\hline \multirow{6}{*}{$\begin{array}{r}\mathrm{C}_{8} \text {-BTBT } \\
\text { /PTAA }\end{array}$} & \multirow{3}{*}{1.0} & 60 & $2.2 \times 10^{-4}$ & $\begin{array}{l}1.8 \times 10^{-4} \\
\left( \pm 3 \times 10^{-5}\right)\end{array}$ & $\begin{array}{c}-12 \\
( \pm 1.2)\end{array}$ & $\sim 10^{3}$ \\
\hline & & 70 & $3.1 \times 10^{-3}$ & $\begin{array}{c}2.1 \times 10^{-3} \\
( \pm 0.1)\end{array}$ & $\begin{array}{l}-30 \\
( \pm 1.8)\end{array}$ & $\sim 10^{4}$ \\
\hline & & 80 & $1.1 \times 10^{-3}$ & $\begin{array}{l}6.1 \times 10^{-4} \\
\left( \pm 2 \times 10^{-4}\right)\end{array}$ & $\begin{array}{c}-16 \\
( \pm 6.1)\end{array}$ & $\sim 10^{3}$ \\
\hline & \multirow{3}{*}{2.0} & 60 & 20.0 & $11.3( \pm 4.8)$ & $\begin{array}{c}-39 \\
( \pm 9.9)\end{array}$ & $\sim 10^{5}$ \\
\hline & & 70 & 19.7 & $12.0( \pm 5.1)$ & $\begin{array}{c}-41 \\
( \pm 13.7)\end{array}$ & $\sim 10^{6}$ \\
\hline & & 80 & 5.1 & $3.5( \pm 1.6)$ & $\begin{array}{c}-20 \\
( \pm 8.4)\end{array}$ & $\sim 10^{4}$ \\
\hline \multirow{7}{*}{$\begin{array}{c}\mathrm{C}_{10} \text {-BTBT } \\
/ \mathrm{PTAA}\end{array}$} & \multirow{3}{*}{1.0} & 60 & 20.6 & $15.2( \pm 3.9)$ & $\begin{array}{l}-48.3 \\
( \pm 1.7)\end{array}$ & $\sim 10^{6}$ \\
\hline & & 70 & 10.8 & $3.6( \pm 3.2)$ & $\begin{array}{c}-51 \\
( \pm 5.3)\end{array}$ & $\sim 10^{5}$ \\
\hline & & 80 & 11.1 & $5.5( \pm 4.3)$ & $\begin{array}{l}-55.5 \\
( \pm 4.1)\end{array}$ & $\sim 10^{4}$ \\
\hline & \multirow{3}{*}{1.5} & 60 & 20.4 & $15.0( \pm 4.3)$ & $\begin{array}{l}-49.1 \\
( \pm 2.9)\end{array}$ & $\sim 10^{6}$ \\
\hline & & 70 & 13.2 & $9.8( \pm 3.3)$ & $\begin{array}{l}-55.1 \\
( \pm 3.1)\end{array}$ & $\sim 10^{5}$ \\
\hline & & 80 & 7.4 & $3.2( \pm 2.2)$ & $\begin{array}{l}-51.2 \\
( \pm 4.2)\end{array}$ & $\sim 10^{4}$ \\
\hline & 2.0 & 60 & 10.5 & $6.7( \pm 2.3)$ & $\begin{array}{c}-39 \\
( \pm 9.3)\end{array}$ & $\sim 10^{6}$ \\
\hline \multirow{2}{*}{$\begin{array}{c}\mathrm{C}_{12} \text {-BTBT } \\
\text { /PTAA }\end{array}$} & \multirow{2}{*}{1.0} & 60 & 17.6 & $8.6( \pm 4.7)$ & $\begin{array}{c}-30 \\
( \pm 9.2)\end{array}$ & $\sim 10^{5}$ \\
\hline & & 70 & 6.3 & $5.7( \pm 0.4)$ & $\begin{array}{c}-32 \\
( \pm 4.1)\end{array}$ & $\sim 10^{4}$ \\
\hline
\end{tabular}




\begin{tabular}{|c|c|c|c|c|c|c|}
\hline $\begin{array}{c}\text { diF- } \\
\text { TESADT } \\
\text { /PTAA }\end{array}$ & 1.0 & 60 & 10.9 & $4.5( \pm 3.9)$ & $\begin{array}{c}-33 \\
( \pm 13.9)\end{array}$ & $\sim 10^{3}$ \\
\hline $\begin{array}{c}\mathrm{C}_{8}-\mathrm{BTBT} \\
/ \mathrm{P} 3 \mathrm{HT}\end{array}$ & 2.0 & 60 & 0.66 & $0.27( \pm 0.4)$ & $\begin{array}{c}80 \\
( \pm 7.8)\end{array}$ & $\sim 10$ \\
\hline \multirow{3}{*}{$\begin{array}{c}\mathrm{C}_{8}-\mathrm{BTBT} \\
\text { /PTAA } \\
\text { (Small } \\
\text { Crystals) }\end{array}$} & \multirow{3}{*}{2.0} & $\begin{array}{c}60 \\
(\mathrm{Gap} 2 \mu \mathrm{m})\end{array}$ & 4.1 & $2.2( \pm 1.3)$ & $\begin{array}{c}-30 \\
( \pm 6.0)\end{array}$ & $\sim 10^{5}$ \\
\hline & & $\begin{array}{c}60 \\
(\text { Gap } 10 \mu \mathrm{m})\end{array}$ & 5.4 & $4.5( \pm 0.6)$ & $\begin{array}{c}-30 \\
( \pm 8.6)\end{array}$ & $\sim 10^{5}$ \\
\hline & & $\begin{array}{c}60 \\
(\text { Gap } 60 \mu \mathrm{m})\end{array}$ & 4.3 & $3.0( \pm 1.2)$ & $\begin{array}{c}-23 \\
( \pm 1.8)\end{array}$ & $\sim 10^{5}$ \\
\hline $\mathrm{C}_{8}$-BTBT & 2.0 & 100 & 4.6 & $4.1( \pm 0.4)$ & $\begin{array}{c}-22 \\
( \pm 2.6)\end{array}$ & $\sim 10^{5}$ \\
\hline
\end{tabular}


Table S5. The comparison of OTFTs in terms of the coating method, coating speed, coating area, and mobility.

\begin{tabular}{cccccc}
\hline Coating Method & $\begin{array}{c}\text { Coating Speed } \\
\left(\mathbf{m m ~ s} \mathbf{~ s}^{-1}\right)\end{array}$ & Coating Area & $\begin{array}{c}\text { Mobility } \\
\left(\mathbf{c m}^{\mathbf{2}} \mathbf{V}^{-1} \mathbf{s}^{-1}\right)\end{array}$ & Reference \\
\hline 1 & Edge-casting & 0.03 & Not available & 9.5 & {$[\mathrm{~S} 2]$} \\
\hline 2 & Blade-coating & $10-30$ & $50 \mu \mathrm{m}^{2}$ & $0.1-0.7$ & {$[\mathrm{~S} 3]$} \\
\hline 3 & Bar-coating & 10 & $180 \times 180 \mu \mathrm{m}^{2}$ & $\sim 0.1$ & {$[\mathrm{~S} 4]$} \\
\hline 4 & Solution-shearing & $0.5-1.0$ & $2 \times 2 \mathrm{~cm}^{2}$ & $13.7-16$ & {$[\mathrm{~S} 5]$} \\
\hline 5 & Edge-casting & 0.02 & Not available & 13 & {$[\mathrm{~S} 6]$} \\
\hline 6 & Solution-shearing & 0.5 & $2 \times 2 \mathrm{~cm}^{2}$ & 3.6 & {$[\mathrm{~S} 7]$} \\
\hline 7 & Bar-coating & $10-30$ & 4 inch wafer & $\sim 20.0$ & This work \\
\hline
\end{tabular}

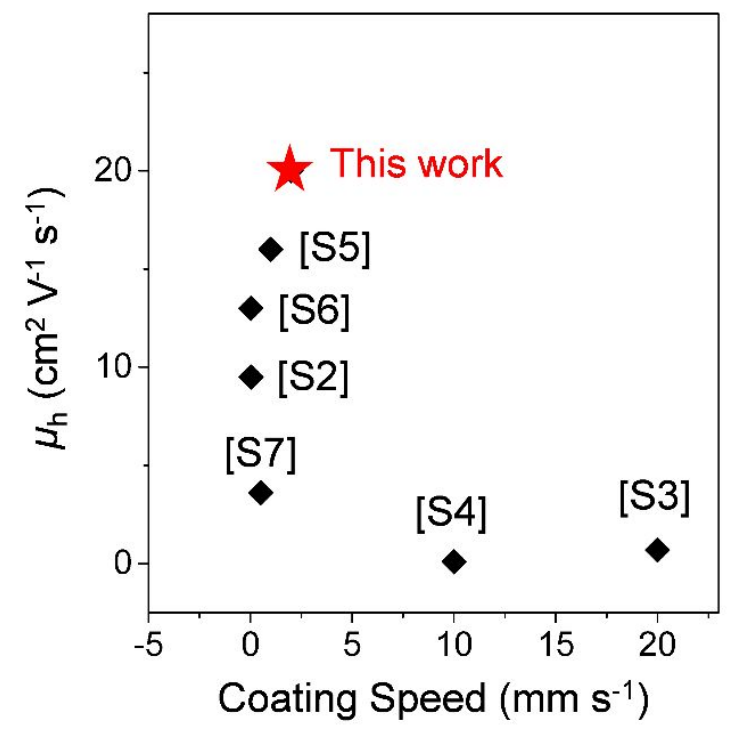

\section{Supporting Movies}

Movie S1. The overall process of bar coating method.

Movie S2. The in-situ POM video of crystal growth at the different gap distances. 


\section{References}

S1. Brandrup, J.; Immergut, E. H.; Grulke, E. A. Polymer Handbook, 1999.

S2. Soeda, J.; Uemura, T.; Okamoto, T.; Mitsui, C.; Yamagishi, M.; Takeya, J. Appl. Phys. Express, 2013, 6, 076503.

S3. Adrien Pierre, M. S.; Payne, Marcia, M.; Facchetti, A.; Anthony, John, E; Arias, C. A. Adv. Mater. 2014, $26,5722$.

S4. del Pozo, F. G.; Fabiano, S.; Pfattner, R.; Georgakopoulos, S.; Galindo, S.; Liu, X.; Braun, S.; Fahlman, M.; Veciana, J.; Rovira, C.; Crispin, X.; Berggren, M.; Mas-Torrent, M. Adv. Funct. Mater. 2015, 26, 2379.

S5. $\quad$ Zhang, Z.; Peng, B.; Ji, X.; Pei, K.; Chan, P. K. L. Adv. Funct. Mater. 2017, 27, 1703443.

S6. $\quad$ Yamamura, S. W. Akifumi; Uno, M.; Mitani, M.; Mitsui, C.; Tsurumi, J.; Isahaya, N.; Kanaoka, Y.; Okamoto, T.; Takeya, J. Sci. Adv. 2018, 4, 5758.

S7. $\quad$ Kim, J. O.; Lee, J. C.; Kim, M. J.; Noh, H.; Yeom, H. I.; Ko, J. B.; Lee, T. H.; Park, S. H. Ko; Kim, D. P.; Park, S. Adv. Mater. 2018, 30, 1800647. 